ORIENTAL JOURNAL OF CHEMISTRY

An International Open Access, Peer Reviewed Research Journal

www.orientjchem.org
ISSN: 0970-020 X

CODEN: OJCHEG

2020, Vol. 36, No.(3):

Pg. 442-445

Brief communication

\title{
Universal pH Indicator as a Colorimetric Reagent for Differentiating Inorganic Anions
}

\author{
JUSTINE GABRIEL K. RODRIGO and VOLTAIRE G. ORGANO* \\ Department of Physical Sciences and Mathematics, College of Arts and Sciences, \\ University of the Philippines, Manila 1000, Philippines. \\ ${ }^{*}$ Corresponding author E-mail: vgorgano@up.edu.ph \\ http://dx.doi.org/10.13005/ojc/360312
}

(Received: May 16, 2020; Accepted: June 23, 2020)

\begin{abstract}
A simple colorimetric approach using a universal $\mathrm{pH}$ indicator to differentiate inorganic anions according to their relative acidity or basicity is presented. Anions caused changes in the $\mathrm{pH}$ of the solution, producing various colors of the universal indicator. Among halides, $\mathrm{F}^{-}$was differentiated from $\mathrm{Cl}^{-}, \mathrm{Br}$ and $\mathrm{I}^{-}$. The indicator was also used on conjugate acid-base pair anions to distinguish $\mathrm{HCO}_{3}{ }^{-}$from $\mathrm{CO}_{3}{ }^{2-}, \mathrm{HSO}_{4}{ }^{-}$from $\mathrm{SO}_{4}{ }^{2-}, \mathrm{HSO}_{3}{ }^{-}$from $\mathrm{SO}_{3}{ }^{2-}$, and various phosphate species. Oxyanions $\mathrm{SO}_{3}{ }^{2-}, \mathrm{HSO}_{3}{ }^{-}, \mathrm{ClO}^{-}, \mathrm{ClO}_{2}{ }^{-}$and $\mathrm{NO}_{2}{ }^{-}$can be differentiated from oxyanions with more oxygens attached, namely, $\mathrm{SO}_{4}^{2-}, \mathrm{HSO}_{4}^{-}, \mathrm{ClO}_{3}^{-}$, and $\mathrm{NO}_{3}^{-}$, respectively. Results can be correlated with the acid ionization constant $K_{a}^{4}$ and/or base hydrolysis constant $K_{b}$ of the anion.
\end{abstract}

Keywords: Colorimetric, Universal pH Indicator, Anion differentiation, $\mathrm{pH}$, Ionization constants.

\section{INTRODUCTION}

Acid-base indicators or $\mathrm{pH}$ indicators are a class of dyes that are common in most chemistry laboratories. These are weak acids or bases of which its undissociated form exhibits a color different from its ionic form. ${ }^{1}$ It has been developed, primarily, for determining the $\mathrm{pH}$ of solutions. However, its application has expanded to include sensing various analytes such as gases, ${ }^{2-7}$ organic compounds, ${ }^{8,9}$ and cations. ${ }^{10,11}$

Recently, our group has shown that anions can be differentiated based on its acidic or basic properties. Using flower pigments ${ }^{12}$ or common laboratory $\mathrm{pH}$ indicators, ${ }^{13}$ different anions change the color of the indicator depending on the $\mathrm{pH}$ produced in solution. This approach has been applied to differentiate conjugate acids and bases such as carbonates, sulfates and phosphates. While flower pigments can be extracted easily from natural sources, its color was found to be unstable for long periods of time and tend to vary depending on the extraction procedure and its source. Common laboratory $\mathrm{pH}$ indicators, on the other hand, are more stable and are readily available. However, the $\mathrm{pH}$ range of individual indicators is limited; thus, requiring several indicator solutions to perform the analysis.

This is an Open Access article licensed under a Creative Commons license: Attribution 4.0 International (CC- BY). Published by Oriental Scientific Publishing Company @ 2018

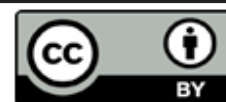


In this study, a universal $\mathrm{pH}$ indicator serves as a "single" colorimetric reagent for the qualitative profiling of anions. This approach is simple, easy to conduct, and requires small amounts of reagents for analysis. The method can have practical applications in chemical education. It can serve as a teaching demonstration or microscale laboratory experiment in senior high school or undergraduate general chemistry, or analytical chemistry class to illustrate solution properties of anions, understand the nature of amphiprotic anions, and relate the effect of equilibrium constants $K_{a}$ and $K_{b}$ to varying anionic species.

\section{MATERIALS AND METHODS}

\section{Materials and Equipment}

Analytical grade sodium and potassium salts used in this study, namely $\mathrm{NaF}, \mathrm{Nal}, \mathrm{Na}_{2} \mathrm{SO}_{4}$, $\mathrm{NaHSO}_{4}, \mathrm{NaHSO}_{3}, \mathrm{Na}_{2} \mathrm{SO}_{3}, \mathrm{NaClO}, \mathrm{NaClO}_{2}, \mathrm{NaNO}_{3}$, $\mathrm{NaNO}_{2}, \mathrm{Na}_{3} \mathrm{PO}_{4}, \mathrm{Na}_{2} \mathrm{HPO}_{4}, \mathrm{NaH}_{2} \mathrm{PO}_{4}, \mathrm{KCl}, \mathrm{KBr}$, $\mathrm{KHSO}_{4}$, and $\mathrm{KClO}_{3}$ were purchased from commercial sources and used without further purification. The universal $\mathrm{pH}$ indicator ( $\mathrm{pH} 4-10)$ was purchased from Sigma-Aldrich ${ }^{\mathrm{TM}}$.

\section{Reagent and Microplate Colorimetry Preparations}

$1.5 \mathrm{~mL}$ of $0.1 \mathrm{M}$ salt solutions in distilled or deionized water were prepared. $0.3 \mathrm{~mL}$ of each solution were placed into 96-well microplates, with one column composed of three wells serving as the three trials for each salt. A separate column was used for the control group (water only). $15.6 \mu \mathrm{L}$ of the universal $\mathrm{pH}$ indicator was added into each test solution.

\section{RESULTS}

One of the most versatile acid-base indicators developed is the universal $\mathrm{pH}$ indicator. ${ }^{14}$ Also known as Yamada Universal Indicator, this solution consists of thymol blue, bromothymol blue, phenolphthalein and methyl red..$^{15}$ It operates at long $\mathrm{pH}$ ranges ( $\mathrm{pH} 4-10)$. In this study, a universal $\mathrm{pH}$ indicator was used as a "single" reagent for differentiating anions. The addition of the universal $\mathrm{pH}$ indicator to individual solutions of anions led to color changes as shown in Figure 1.

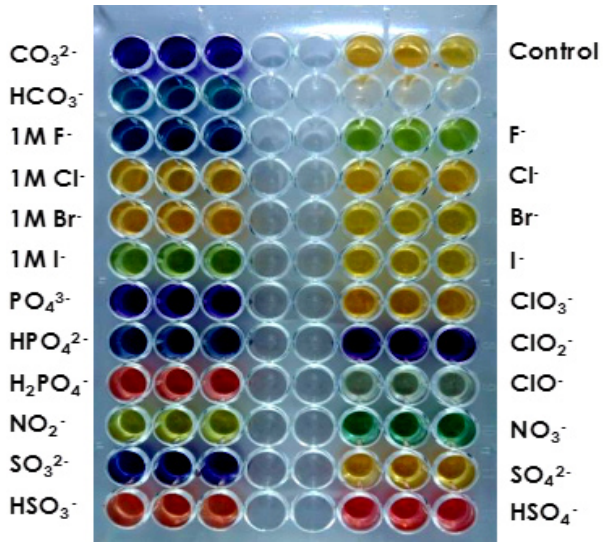

Fig. 1. Microplate wells containing $0.1 \mathrm{M}$ anion solutions (unless otherwise indicated) in distilled water with a universal $\mathrm{pH}$ indicator solution. Tests were done in triplicates

Among the halides, $\mathrm{F}^{-}, \mathrm{Cl}^{-}, \mathrm{Br}^{-}$, and $\mathrm{I}^{-}$, only $\mathrm{F}^{-}$was generally distinct from the others. $\mathrm{F}^{-}$led to an olive-green solution while other halides have colors similar to the control solution at $0.1 \mathrm{M}$ concentration. At a higher concentration ( $1 \mathrm{M}), \mathrm{F}^{-}$is still significantly different from $\mathrm{Cl}^{-}, \mathrm{Br}^{-}$, and $\mathrm{I}^{-}$, but the color has turned to blue. Moreover, $\mathrm{I}^{-}$could now be distinguished from the other halides with a color change from yellow to olive-green. This observation may be attributed to an increase in ionic strength of halide solutions which caused a shift in the color of the indicator. This behavior has also been noted by Rodriguez and Mirenda ${ }^{16}$ in which an increase in salt concentration led to a shift of the $\mathrm{pH}$ indicator towards the basic form. Thus, it is important to compare anions with the same concentration and under dilute conditions.

Conjugate acids/bases were also distinguished from each other. It was observed that the color of the $\mathrm{SO}_{4}{ }^{2-}$ solution is yellow while that of $\mathrm{HSO}_{4}^{-}$is red. Meanwhile, $\mathrm{SO}_{3}{ }^{2-}$ was notably violet while $\mathrm{HSO}_{3}{ }^{-}$was red-orange. Different phosphate species exhibited different colors: $\mathrm{PO}_{4}{ }^{3-}$ is violet, $\mathrm{HPO}_{4}{ }^{2-}$ is blue, and $\mathrm{H}_{2} \mathrm{PO}_{4}^{-}$is orange. It was also observed that $\mathrm{CO}_{3}^{2-}$ is violet while $\mathrm{HCO}_{3}^{-}$is blue. As expected, the conjugate acid form of the anion tends to shift the color of the indicator towards the acidic color relative to its basic color.

Finally, oxyanion pairs sulfate-sulfite, bisulfate-bisulfite, nitrate-nitrite, and oxychlorides were also differentiated from each other. Lessoxygenated oxyanions $\mathrm{SO}_{3}{ }^{2-}$ and $\mathrm{ClO}_{2}^{-}$resulted in blue to violet colors. $\mathrm{ClO}^{-}$, at the onset, is violet but 
eventually turns to light green, then colorless. It should be noted that hypochlorite, $\mathrm{ClO}^{-}$, is a widely-used bleach and a strong oxidant, and is known to degrade dyes. ${ }^{17,18}$ Meanwhile, oxyanions with a higher number of oxygen atoms attached, $\mathrm{SO}_{4}{ }^{2-}$ and $\mathrm{ClO}_{3}{ }^{-}$, result in a yellow solution. On the other hand, for oxyanions $\mathrm{NO}_{3}^{-}$and $\mathrm{NO}_{2}^{-}$, nitrate exhibited a dark green color, while nitrite ion yielded a yellow-green solution.

The analysis was also performed in degassed distilled and degassed deionized water. Similar results were obtained as those for simple distilled water. This implies that minimal impurities like dissolved gases in the air do not significantly affect the results of the analysis.

\section{DISCUSSION}

The colors observed for anion solutions correlate well to the colors of the indicator at a given $\mathrm{pH}$ of the solution. This was verified using a $\mathrm{pH}$ meter. Conjugate bases and less ${ }^{-}$oxygenated oxychlorides $\mathrm{ClO}_{2}^{-}, \mathrm{ClO}^{-}, \mathrm{CO}_{3}{ }^{2-}$ and $\mathrm{PO}_{4}{ }^{3-}$ with $\mathrm{pH}$ of 10 or greater exhibited a violet color. $\mathrm{SO}_{3}{ }^{2-}$ and $\mathrm{HPO}_{4}^{2-}$ with $\mathrm{pH} 9$ to less than 10 imparted a blue solution. $\mathrm{HCO}_{3}^{-}$with $\mathrm{pH}$ ranging from 8 to less than 9 yielded a blue-green color. On the other hand, $\mathrm{NO}_{3}^{-}$and $\mathrm{F}^{-}$with $\mathrm{pH} 7$ to less than 8 presented a green color. Oxyanions $\mathrm{SO}_{4}{ }^{2-}, \mathrm{ClO}_{3}{ }^{-}$and $\mathrm{NO}_{2}{ }^{-}$with $\mathrm{pH}$ from 6.4 to less than 7 displayed a yellow-green solution. Meanwhile, halides $\mathrm{I}^{-}, \mathrm{Cl}^{-}$, and $\mathrm{Br}$ with $\mathrm{pH}$ from 6 to less than 6.4 imparted a yellow color. For protonated anions, $\mathrm{H}_{2} \mathrm{PO}_{4}^{-}(\mathrm{pH} 4-5)$ gave off orange color, while $\mathrm{HSO}_{3}^{-}$and $\mathrm{HSO}_{4}^{-}(\mathrm{pH}<4)$ yielded redorange or red, respectively.

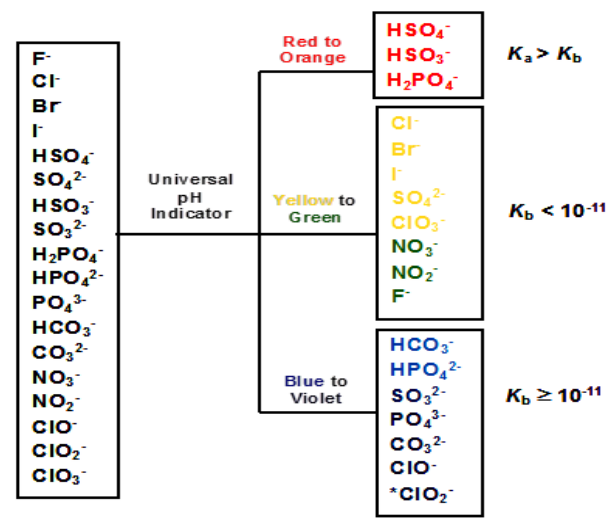

Fig. 2. Diagram for grouping anions based on the color of indicator and its ionization constants $K_{a}$, or $K_{b} \cdot{ }^{*}$ Chlorite is the only exception as its $K_{b}<10^{-11}$
Aside from $\mathrm{pH}$, the color of the solution imparted by anions can be correlated to its acid ionization constant $\left(K_{\mathrm{a}}\right)$ or base hydrolysis constant $\left(K_{b}\right) .{ }^{19}$ This allows grouping of anions based on its acidic or basic properties as shown in Fig. 2. Anions which turn the $\mathrm{pH}$ indicator to red or red-orange $\left(\mathrm{HSO}_{4}^{-}, \mathrm{HSO}_{3}^{-}\right.$and $\left.\mathrm{H}_{2} \mathrm{PO}_{4}^{-}\right)$are protonated species and were found to have $K_{a}$ values greater than its $K_{b}$ (Table 1). Thus, these anions tend to produce more $\mathrm{H}_{3} \mathrm{O}^{+}$in solution via acid ionization than $\mathrm{OH}^{-}$ions produced via base hydrolysis, as exemplified by $\mathrm{HSO}_{4}^{-}$in Figure 3.

Table 1: Acid ionization and base hydrolysis constants for protonated anions

\begin{tabular}{lcc}
\hline Anion & $\begin{array}{c}\text { Acid lionization } \\
\text { constant }\left(K_{a}\right)^{19}\end{array}$ & $\begin{array}{c}\text { Base Hydrolysis } \\
\text { constant }\left(K_{b}\right)^{*}\end{array}$ \\
\hline $\mathrm{HSO}_{4}^{-}$ & $1.2 \times 10^{-2}$ & $\begin{array}{c}\text { Very small } \\
\mathrm{HSO}_{3}^{-}\end{array}$ \\
$\mathrm{H}_{2} \mathrm{PO}_{4}^{-}$ & $6.3 \times 10^{-8}$ & $8.3 \times 10^{-13}$ \\
\end{tabular}

${ }^{\star}$ Calculated from $K_{b}=K_{w} / K_{a}$ where $K_{w}$ is the ionization constant of water, and $K_{a}$ is ionization constant of the conjugate acid of the anion.

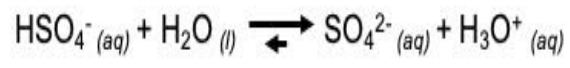

acid ionization

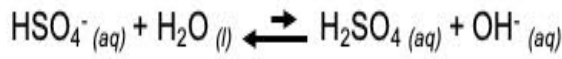

$$
\begin{aligned}
& \text { base hydrolysis }
\end{aligned}
$$

Fig. 3. Acid ionization and base hydrolysis reactions involving $\mathrm{HSO}_{4}^{-}$

On the other hand, anions that turn the $\mathrm{pH}$ indicator to yellow or yellow-green $\left(\mathrm{Cl}^{-}, \mathrm{Br}^{-}, \mathrm{I}^{-}, \mathrm{SO}_{4}{ }^{2-}\right.$, $\mathrm{NO}_{2}^{-}$and $\mathrm{ClO}_{3}^{-}$) or green $\left(\mathrm{F}^{-}\right.$and $\left.\mathrm{NO}_{3}^{-}\right)$were found to have $K_{b}$ values less than $10^{-11}$. Finally, anions that turn the $\mathrm{pH}$ indicator to blue or violet $\left(\mathrm{ClO}_{2}^{-}, \mathrm{SO}_{3}{ }^{2-}\right.$, $\mathrm{HPO}_{4}^{-}, \mathrm{PO}_{4}{ }^{3-}, \mathrm{HCO}_{3}^{-}, \mathrm{CO}_{3}{ }^{2-}$ and $\mathrm{ClO}^{-}$) are relatively basic. These anions, except for $\mathrm{ClO}_{2}^{-}\left(K_{b}=8 \times 10^{-13}\right)$, were found to have $K_{b}$ values greater than or equal to $10^{-11}$.

\section{CONCLUSION}

A universal $\mathrm{pH}$ indicator solution was used to differentiate inorganic anions. The indicator was able to differentiate $\mathrm{F}^{-}$from the other halides. Protonated anions $\left(\mathrm{HSO}_{4}^{-}, \mathrm{HSO}_{3}^{-}\right.$and $\left.\mathrm{H}_{2} \mathrm{PO}_{4}^{-}\right)$were 
also differentiated from its conjugate base pairs $\left(\mathrm{SO}_{4}{ }^{2-}, \mathrm{SO}_{3}{ }^{2-}, \mathrm{HPO}_{4}{ }^{2-}\right.$ and $\left.\mathrm{PO}_{4}{ }^{3-}\right)$. Oxyanions $\mathrm{SO}_{3}{ }^{2-}$, $\mathrm{HSO}_{3}^{-}, \mathrm{NO}_{2}^{-}, \mathrm{ClO}^{-}$and $\mathrm{ClO}_{2}^{-}$were differentiated from oxyanions with more oxygen atoms attached, namely $\mathrm{SO}_{4}^{2-}, \mathrm{HSO}_{4}^{-}, \mathrm{NO}_{3}^{-}$and $\mathrm{ClO}_{3}^{-}$. The color produced can be correlated with the $\mathrm{pH}$ of the solution and corresponding acid ionization constant $K_{a}$ and/or base hydrolysis constant $K_{b}$ of the anion.

This approach is simple and can be used as a demonstration or laboratory experiment in high school or freshmen college chemistry to help learners understand the acidic or basic nature of anions. It also applies principles of chemical equilibrium, ionization constants, and nature of amphiprotic anions through visual observation.

\section{ACKNOWLEDGMENT}

This research work was conducted under the Research Grants Administration Office (RGAO-20160835) of the University of the Philippines Manila.

\section{Conflict of interest}

No conflict of interest.

\section{REFERENCES}

1. Sabnis, R. W. Handbook of Acid-Base Indicators; CRC Press., 2007.

2. Solomon, S.; Oliver-Hoyo, M.; Hur, C. Generating Water-Soluble Noxious Gases: An Overhead Projector Demonstration. J. Chem. Educ., 1998, 75(12), 1581-1582.

3. Carvalho, A. P.; Mendonça, Å. F.S.S.; Piedade, M. F. M. Acid-Base Reactions with Carbon Dioxide. J. Chem. Educ., 2002, 79 (12), 1464A.

4. Mills, A.; Skinner, G. A.; Grosshans, P. Intelligent Pigments and Plastics for $\mathrm{CO}_{2}$ Detection. J. Mater. Chem., 2010, 20, 5008-5010.

5. Rodríguez, A. J.; Zamarreño, C. R.; Matías, I. R.; Arregui, F. J.; Cruz, R. F. D.; May-Arrioja, D. A. A Fiber Optic Ammonia Sensor Using a Universal pH Indicator. Sensors (Switzerland) 2014, 14(3), 4060-4073.

6. Feng, L.; Musto, C. J.; Kemling, J.W.; Lim, S. H.; Zhong, W.; Suslick, K. S. Colorimetric Sensor Array for Determination and Identification of Toxic Industrial Chemicals. Anal. Chem., 2010, 82(22), 9433-9440.

7. Feng, L.; Musto, C. J.; Kemling, J. W.; Lim, S. H.; Suslick, K. S. A Colorimetric Sensor Array for Identification of Toxic Gases below Permissible Exposure Limits. Chem. Commun., 2010, 46, 2037-2039.

8. Lim, S. H.; Musto, C. J.; Park, E.; Zhong, W.; Suslick, K. S. A Colorimetric Sensor Array for Detection and Identification of Sugars. Org. Lett., 2008, 10(20), 4405-4408.

9. Zhang, C.; Suslick, K. S. A Colorimetric Sensor Array for Organics in Water. J. Am. Chem. Soc., 2005, 127(33), 11548-11549.

10. Gokulan, G.; Nagarajan, D.; Venkatanarasimhan, S.; Sathish, A. Ixora Coccinea Floral Extract Coated Ear Buds-Highly Selective and Eco-Friendly Sensor for the Detection of $\mathrm{Pb}(\mathrm{II})$ lons. J. Environ. Chem.
Eng., 2019, 7(4), 103230.

11. Porrawatkul, P.; Pimsen, R.; Kuyyogsuy, A.; Nuengmatcha, P. Simple and Selective Naked-Eye Detection of $\mathrm{Cu}^{2+}$ and $\mathrm{Al}^{3+}$ using Hibiscus rosa-sinensis Linn Flower Extract. Orient. J. Chem., 2018, 34(1), 188-195.

12. Galingana, M. O.; Organo, V. G. A Simple Colorimetric Procedure for Differentiating Anions Using Flower Pigments from Anthurium andreanum. Orient. J. Chem., 2016, 32(3), 1347-1352.

13. Punzalan, J. M.; Organo, V. G. Are Aqueous Solutions of Amphiprotic Anions Acidic, Basic, or Neutral? A Demonstration with Common pH Indicators. J. Chem. Educ., 2017, 94(7), 911-915.

14. Myers, R. J. One-Hundred $Y$ ears of $P H . J$. Chem. Educ., 2010, 87(1), 30-32.

15. Foster, L. S.; Gruntfest, I. J. Demonstration Experiments Using Universal Indicators. J. Chem. Educ., 1937, 14(6), 274-275.

16. Rodríguez, H. B.; Mirenda, M. A Simplified Undergraduate Laboratory Experiment to Evaluate the Effect of the Ionic Strength on the Equilibrium Concentration Quotient of the Bromcresol Green Dye. J. Chem. Educ., 2012, 89(9), 1201-1204.

17. Oakes, J.; Gratton, P.; Gordon-Smith, T. Combined Kinetic and Spectroscopic Study of Oxidation of Azo Dyes in Surfactant Solutions by Hypochlorite. Dyes and Pigments., 2000, 46(3), 169-180.

18. Oakes, J.; Gratton, P. Kinetic Investigations of Azo Dye Oxidation in Aqueous Media. J. Chem. Soc. Perkin Trans., 1998, 2(9), 1857-1864.

19. Perrin, D.D. Dissociation Constants of Inorganic Acids and Bases in Aqueous Solution. Pure Appl. Chem., 1969, 20(2), 133-236. 